\title{
Pembangunan Aplikasi E-Commerce Pemasaran Sepatu pada Toko Ranch_19
}

\author{
Irsyad Rafi Arsalan*)1), Aziz Setyawan Hidayat ${ }^{2)}$, \\ Eva Rahmawati ${ }^{3)}$, Pas Mahyu Akhirianto ${ }^{4}$ \\ ${ }^{133)}$ Sekolah Tinggi Manajemen Informatika dan Komputer Nusa Mandiri \\ ${ }^{2) 4}$ Universitas Bina Sarana Informatika PSDKU Tegal \\ ${ }^{*}$ Correspondence author: rafirebek25@gmail.com, DKI Jakarta, Indonesia
}

\begin{abstract}
Abstrak
Dalam pemasarannya Toko Sepatu Ranch_19 Jakarta belum menggunakan fasilitas internet sehingga kesulitan dalam menawarkan produk kepada pelanggan yang berada di luar kota. Proses penjualan Toko Sepatu Ranch_19 Jakarta hanya dilakukan apabila terdapat pelanggan yang datang ke toko tersebut. Berdasarkan masalah tersebut membangun aplikasi yang berbasis e-commerce dapat menjadi solusi pemecahan masalah yang menggunakan teknik pemrosesan data yang mengacu pada sebuah komputasi yang diinginkan atau diharapkan. Model pengembangan sistem yang digunakan dalam penelitian ini menggunakan model waterfall atau air terjun. Waterfall adalah salah satu metoda pengembangan perangkat lunak. Hasil dari penelitian ini adalah membangun aplikasi e-commerce yang berbasis website agar penyebaran informasiinformasi produk pada Toko Sepatu Ranch_19 Jakarta lebih luas, mengakomodir semua transaksi yang terjadi pada Toko Sepatu Ranch_19 Jakarta secara detail dengan komputerisasi dan membangun aplikasi ecommerce yang berbasis website sebagai solusi untuk kontrol oleh pemilik Toko Sepatu Ranch_19 Jakarta.
\end{abstract}

Kata Kunci: Aplikasi, E-Commerce, Pemasaran, Toko Sepatu

\begin{abstract}
In marketing the Shoe Shop Ranch_19 Jakarta has not used internet facilities so it is difficult to offer products to customers who are outside the city. The sales process of the Jakarta Ranch_19 Shoe Shop is only carried out if there are customers who come to the store. Based on these problems building e-commerce based applications can be a problem solving solution that uses data processing techniques that refer to a desired or expected computation. The system development model used in this study uses the waterfall model. Waterfall is one of the methods of software development. The results of this research are building a websitebased e-commerce application so that the dissemination of product information at the Jakarta Ranch_19 Shoe Store is wider, accommodating all transactions that occur at the Jakarta Ranch_19 Shoe Store in detail with computerization and building a website-based e-commerce application as a solution for control by the owner of the Jakarta Shoe Store Ranch_19.
\end{abstract}

Keywords: Application, E-Commerce, Marketing, Shoe Shop

\section{PENDAHULUAN}

Kebutuhan akan teknologi informasi pada era globalisasi sekarang ini makin penting sehubungan dengan tujuan informasi yaitu menghasilkan sesuatu yang lebih berguna dan berarti demi pengambilan suatu keputusan secara cepat dan akurat. Perubahan dan dinamika masyarakat semakin cepat seiring dengan perkembangan zaman dan teknologi. Penggunaan Teknologi informasi dapat diterapkan dalam berbagai bidang, diantaranya bidang perdagangan. Perdagangan produk dengan bertemu langsung antara penjual dan pembeli sudah tidak asing lagi, karena pada dasarnya perdagangan sekarang ini dilakukan dengan seperti itu. 
Toko Sepatu Ranch_19 Jakarta yang berlokasi di Jl. Muara Dalam No. 40 Rt. 006 Rw. 003 Kel. Tanjung Barat Kec. Jagakarsa Jakarta Selatan merupakan toko sepatu yang menjual berbagai macam sepatu olah raga dan sepatu buat santai terutama untuk laki-laki. Toko sepatu ini menjual bermacam-macam merek sepatu yang sedang diminati anak-anak muda. Toko Sepatu Ranch_19 Jakarta mengikuti perkembangan model-model yang baru menyesuaikan dengan selera anak muda masa kini.

Pada saat ini, Toko Sepatu Ranch_19 Jakarta belum menggunakan fasilitas internet sehingga kesulitan dalam menawarkan produk kepada pelanggan yang berada di luar kota. Selain itu, juga bisa mengakibatkan dampak yang berpengaruh kepada proses penjualan produk yaitu ketidaktahuan pelanggan yang berada di luar kota akan keberadaan Toko Sepatu Ranch_19 Jakarta. Proses penjualan Toko Sepatu Ranch_19 Jakarta hanya dilakukan apabila terdapat pelanggan yang datang ke toko tersebut, sementara banyak pelanggan yang di luar kota tidak bisa datang atau tidak tahu keberadaan Toko Sepatu Ranch_19 Jakarta.

Adapun penelitian yang terkait dengan topik ini antara lain:

Menurut (Dirgahinta \& Anwar, 2018) menyatakan bahwa penjualan yang dijalankan oleh Toko Pantes masih sebatas transaksi offline dimana proses jual beli dilakukan secara langsung. Pembeli datang ke Toko Pantes untuk membeli sepatu yang diinginkan sehingga dapat menyita waktu untuk melakukan proses jual-beli secara langsung. Mekanisme penjualan menggunakan brosur dan pamflet dirasa masih kurang maksimal karena kurangnya informasi yang diberikan mengenai detail sepatu yang ditawarkan, penjualan menggunakan blog juga dirasa pelanggan kurang bagus karena blog tidak bisa melakukan transaksi penjualan sepatu. Blog Toko Pantes saat ini hanya menampilkan informasi kontak Toko Pantes dan belum dapat memberikan rekomendasi kepada pelanggan tentang sepatu yang sesuai dengan keinginan pelanggan. Kesimpulan penelitiannya yaitu dengan adanya aplikasi e-commerce penjualan sepatu dengan sistem rekomendasi berbasis cross selling pada Toko Pantes dapat memudahkan pelanggan untuk memesan sepatu tanpa batasan waktu dan tempat serta memudahkan pelanggan untuk memperoleh informasi barang pada Toko Pantes dengan cepat dan mudah.

Perkembangan teknologi dimasa sekarang ini menuntut Toko Sepatu Ranch_19 Jakarta harus mengikutinya agar dapat bersaing dengan toko-toko sepatu lainnya. Penjualan dengan media sosial belum cukup untuk menyaingi toko-toko sepatu lain yang lebih besar sehingga diperlukan cara agar dapat bersaing dalam perkembangan bisnisnya. Salah satu cara yang tepat untuk bersaing dalam penjualan sepatu ini adalah dengan merancang satu 
website yang bisa mendukung kelancaran jalannya operasional penjualan sepatu pada Toko Sepatu Ranch_19 Jakarta.

Dengan adanya sistem informasi penjualan berbasis e-commerce dapat memudahkan konsumen dalam melakukan pemesanan barang secara online, karena konsumen tidak perlu datang langsung ke toko.(Handayani, 2018). Pemakaian sistem e-commerce sangat menguntungkan banyak pihak, baik konsumen, produsen maupun penjual. (Lesmono, 2018).

Menurut (Imaniawan \& Elsa, 2017) menyatakan bahwa "Sistem informasi penjualan sepatu berbasis website ini untuk digunakan sebagai media penyimpanan dan pengelolaan data bagi pemilik agar lebih efisien dan efektif dalam pengembangan usahanya”.

Hasil dari perkembangan teknologi saat ini adalah munculnya website yang memanfaatkan kemampuan komputer langsung untuk melakukan suatu tugas yang diinginkan pengguna. Website dapat menjadi solusi pemecahan masalah yang menggunakan teknik pemrosesan data yang mengacu pada sebuah komputasi yang diinginkan atau diharapkan.

Hal tersebut menjadi fokus perhatian penulis pada saat melakukan penelitian di Toko Sepatu Ranch_19 Jakarta dan penulis bermaksud memberikan solusi untuk mengatasi permasalahan yang dihadapi dalam proses pengolahan data penjualan dengan membangun sistem informasi penjualan sepatu berbasis website.

\section{METODE}

Dalam penelitian ini penulis menggunakan dua metode yaitu metode pengumpulan data dan metode pengembangan sistem yang dijelaskan sebagai berikut:

Teknik pengumpulan data merupakan faktor penting demi keberhasilan penelitian. Hal ini berkaitan dengan bagaimana cara mengumpulkan data, siapa sumbernya, dan apa alat yang digunakan. Berikut ini merupakan teknik pengumpulan data yang digunakan :

1. Observasi

Penulis melihat secara langsung di Toko Sepatu Ranch_19 Jakarta Jl. Muara Dalam No. 40 Rt. 006 Rw. 003 Kel. Tanjung Barat Kec. Jagakarsa Jakarta Selatan dan melakukan pengamatan pada bagian penjualan, sehingga mendapatkan gambaran yang lengkap dan jelas mengenai prosedur penjualan, prosedur pengolahan data penjualan. Selain itu penulis juga mencari informasi yang jelas mengenai permasalahan yang terjadi pada prosedur penjualan di Toko Sepatu Ranch_19 Jakarta.

2. Wawancara

Penulis melakukan tanya jawab dengan bagian penjualan dan Bapak Azmi Baihaqi selaku pemilik Toko Sepatu Ranch_19 Jakarta tentang masalah yang masih kurang 
jelas pada saat melakukan observasi, selain itu penulis juga melakukan wawancara dengan pelanggan yang berkunjung ke Toko Sepatu Ranch_19 Jakarta.

3. Studi Pustaka

Penulis mencari referensi dari buku, jurnal, e-book dan juga informasi dari internet yang berkaitan dengan materi yang penulis bahas merupakan tambahan untuk melengkapi penulisan penelitian ini.

Metode pengembangan sistem yang digunakan dalam penelitian ini menggunakan metode waterfall atau air terjun. Waterfall adalah metode yang dikembangkan untuk pengembangan perangkat lunak. Model berkembang secara sistematis dari satu tahap ke tahap lain dalam mode seperti air terjun. Model pengembangan ini bersifat linear dari tahap awal pengembangan sistem yaitu tahap perencanaan sampai tahap akhir pengembangan system yaitu tahap pemeliharaan. Tahapan berikutnya tidak akan dilaksanakan sebelum tahapan sebelumnya selesai dilaksanakan dan tidak bisa kembali atau mengulang ke tahap sebelumnya. (Lubis, 2016). Berikut adalah tahapan-tahapan yang penulis lakukan dalam pengembangan sistem.

1. Analisa Kebutuhan Software

Kebutuhan pada website ini yaitu informasi pengolahan data penjulan Toko Sepatu Ranch_19 Jakarta. Kebutuhan software meliputi input data produk, input data pelanggan, input data pembelian oleh pelanggan sampai dengan hasil pengolahan data penjualan, input data pengiriman dan laporan penjualan yang dapat dilihat oleh pemilik Toko Sepatu Ranch_19 Jakarta. Software yang dibutuhkan yaitu Adobe Dreamweaver CS4 dan Adobe Photoshop CS 3 serta database MySQL dalam aplikasi phpmyadmin dan database server Xampp.

\section{Desain}

Dalam merancang website ini penulis menggunakan pemrograman terstruktur dan mengkombinasikan dua tools yaitu tools system dan tools application, pada tools system menggunakan Unified Modelling Language (UML) meliputi Use Case Diagram dan Activity Diagram. Untuk desain databasenya menggunakan Entity Relationship Diagram (ERD). Selain itu digunakan juga Component Diagram dan Deployment Diagram. Untuk tools aplication penulis menggunakan Adobe Dreamweaver CS4.

\section{Code Generation}

Desain yang dibuat harus diterjemahkan dalam bahasa mesin. Bahasa mesin dalam desain yang digunakan adalah terstruktur. Dimana penulis memilih kode program yang mengidentifikasi dan mengorganisasi domain aplikasi. Pada tahap ini dapat dilalui 
dengan mudah dengan menggunakan bahasa pemrograman PHP dibantu database MySQL dalam aplikasi phpmyadmin dan database server Xampp.

\section{Testing}

Untuk melakukan pengetesan program yang sudah dibuat, apakah sudah benar atau belum, sudah sesuai atau belum, diuji dengan cara manual yaitu dengan menggunakan blackbox. Apabila ditemukan error pada website pada saat website digunakan maka dapat dengan mudah dicari penyebabnya. Sebelum website ini dapat di akses oleh pelanggan, penulis menggunakan blackbox testing dengan melakukan pengecekan terlebih dahulu seperti form login pelanggan dan form login pemilik sebagai administrator dan mencoba seluruh komponen yang ada dalam aplikasi sehingga meminimalisir kesalahan.

\section{Support}

Dalam mendukung aplikasi yang akan dikerjakan diperlukan perangkat keras (hardware), yaitu peralatan dalam bentuk fisik yang menjalankan perangkat lunak (software) dan peralatan ini berfungsi untuk menjalankan instruksi-instruksi yang diberikan dan mengeluarkannya dalam bentuk informasi. Untuk memenuhi terciptanya web tersebut penulis menggunakan hardware dengan sfesifikasi Processor Intel Core I3 M380.

\section{HASIL DAN PEMBAHASAN}

Sistem penjualan pada Toko Sepatu Ranch_19 Jakarta secara online berbasis website dimana calon pelanggan dan penjual tidak bertatap muka secara langsung. Calon pelanggan melakukan pembelian melalui media browser. Berikut ini spesifikasi kebutuhan (system requirement) dari sistem penjualan pada Toko Sepatu Ranch_19 Jakarta secara online berbasis website.

1) Halaman Pelanggan:

A1.Pelanggan dapat melihat produk berdasarkan kategori

A2.Pelanggan dapat melihat produk berdasarkan merek

A3.Pelanggan dapat melihat cara pembelian

A4.Pelanggan dapat melihat cara pembayaran

A5.Pelanggan dapat melihat tentang Toko Sepatu Ranch_19 Jakarta

A6.Pelanggan dapat melakukan pendaftaran.

A7.Pelanggan dapat melakukan login dengan account yang telah dibuat apabila melakukan pembelian dilain hari

A8.Pelanggan dapat melakukan pembeliaan 
A9.Pelanggan bisa melakukan konfirmasi pembayaran.

2) Halaman Administrator:

B1. Administrator dapat mengelola data sepatu.

B2. Administrator dapat mengelola data pelanggan.

B3. Administrator dapat mengelola transaksi penjualan.

B4. Administrator dapat mengelola laporan penjualan.

Use Case Diagram Pembelian Sepatu pada Toko Sepatu Ranch_19 Jakarta Online adalah sebagai berikut:

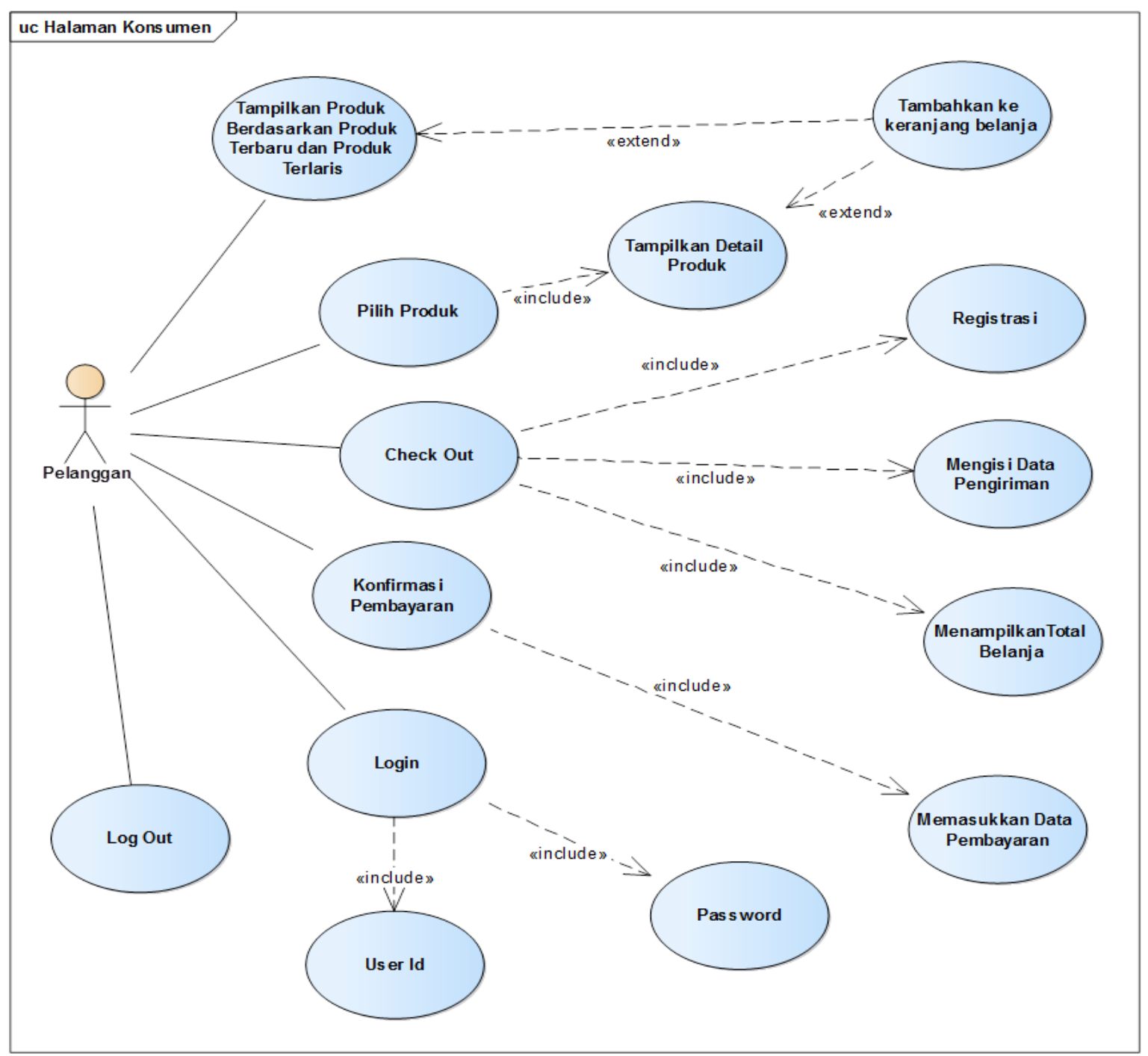

Gambar 1. Use Case Diagram Pembelian Sepatu pada Toko Sepatu Ranch_19 


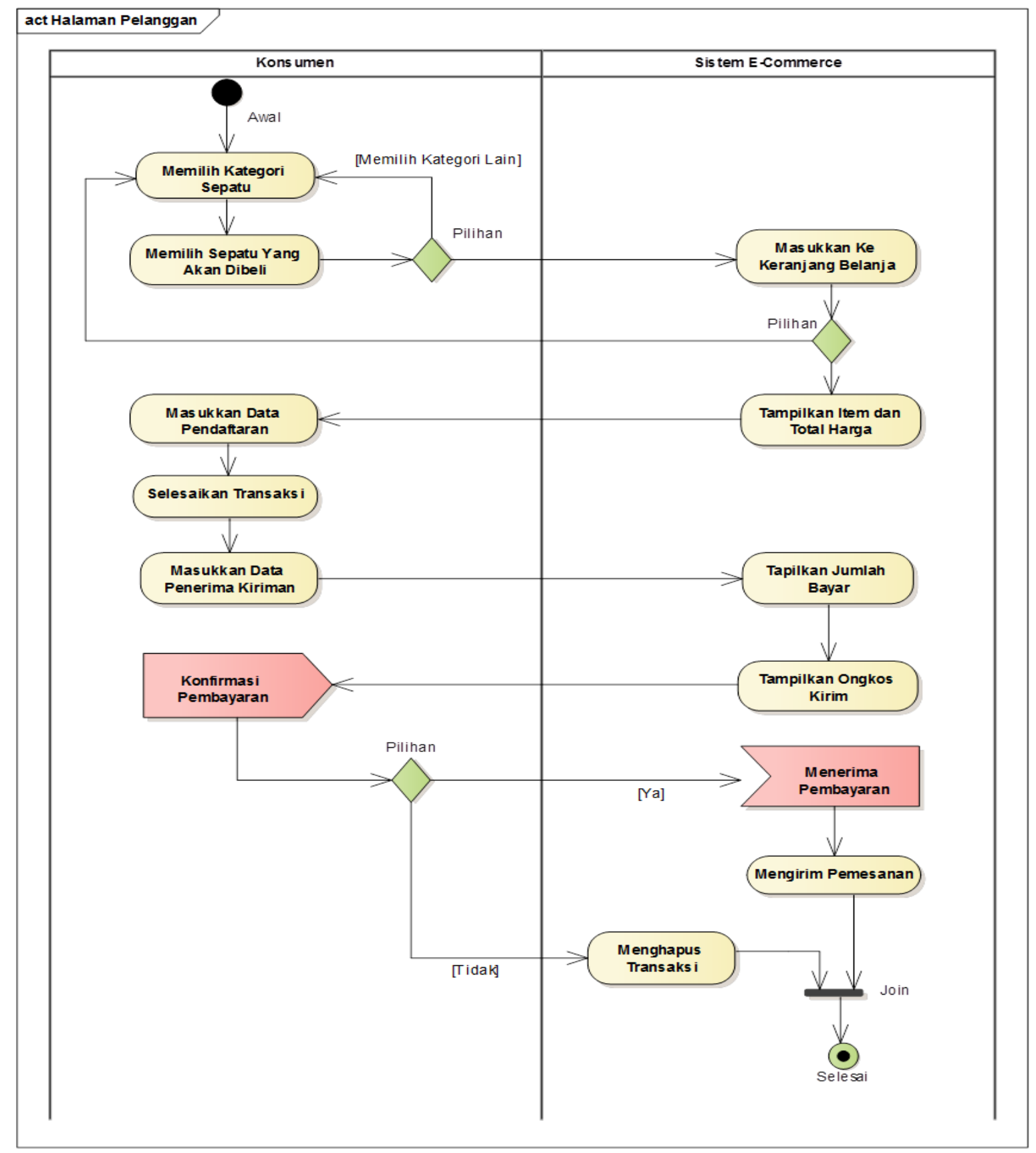

Gambar 2. Acivity Diagram Belanja Online Halaman Pelanggan

Dalam penelitian ini rancangan basis data dalam bentuk Entity Relationship Diagram sebagai berikut: 


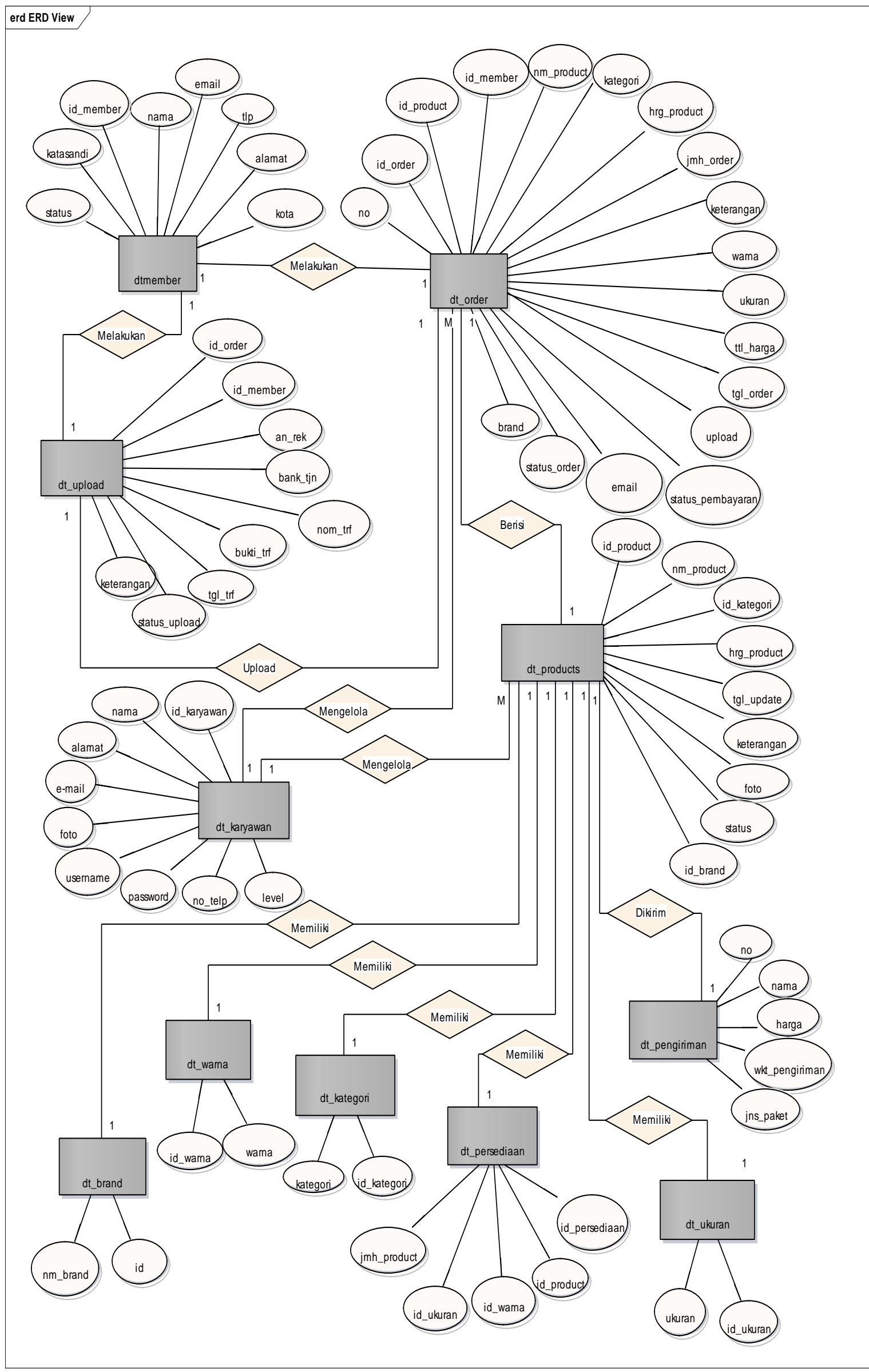

Gambar 3. Entity Relationship Diagram 
Spesifikasi file diantaranya sebagai berikut:

Tabel 1.

Spesifikasi Tabel Data Member

\begin{tabular}{clllll}
\hline No & Elemen Data & Nama Field & Type & Size & Keterangan \\
\hline 1 & Id Member & id_member & varchar & 20 & Primary Key \\
2 & Nama & nama & varchar & 50 & \\
3 & Email & email & varchar & 50 & \\
4 & Telpon & tlp & varchar & 15 & \\
5 & Alamat & alamat & varchar & 100 & \\
\hline
\end{tabular}

Tabel 2.

Spesifikasi Tabel Data Persediaan

\begin{tabular}{clllll}
\hline No & Elemen Data & Nama Field & Type & Size & Keterangan \\
\hline 1 & Id Persediaan & id_persediaan & int & 11 & Primary Key \\
2 & Id Product & id_product & varchar & 8 & \\
3 & Id Warna & id_warna & int & 11 & \\
4 & Id Ukuran & id_ukuran & int & 11 & \\
5 & Jumlah Product & jmh_product & int & 11 & \\
\hline
\end{tabular}

Berikut merupakan tampilan Component Diagram:

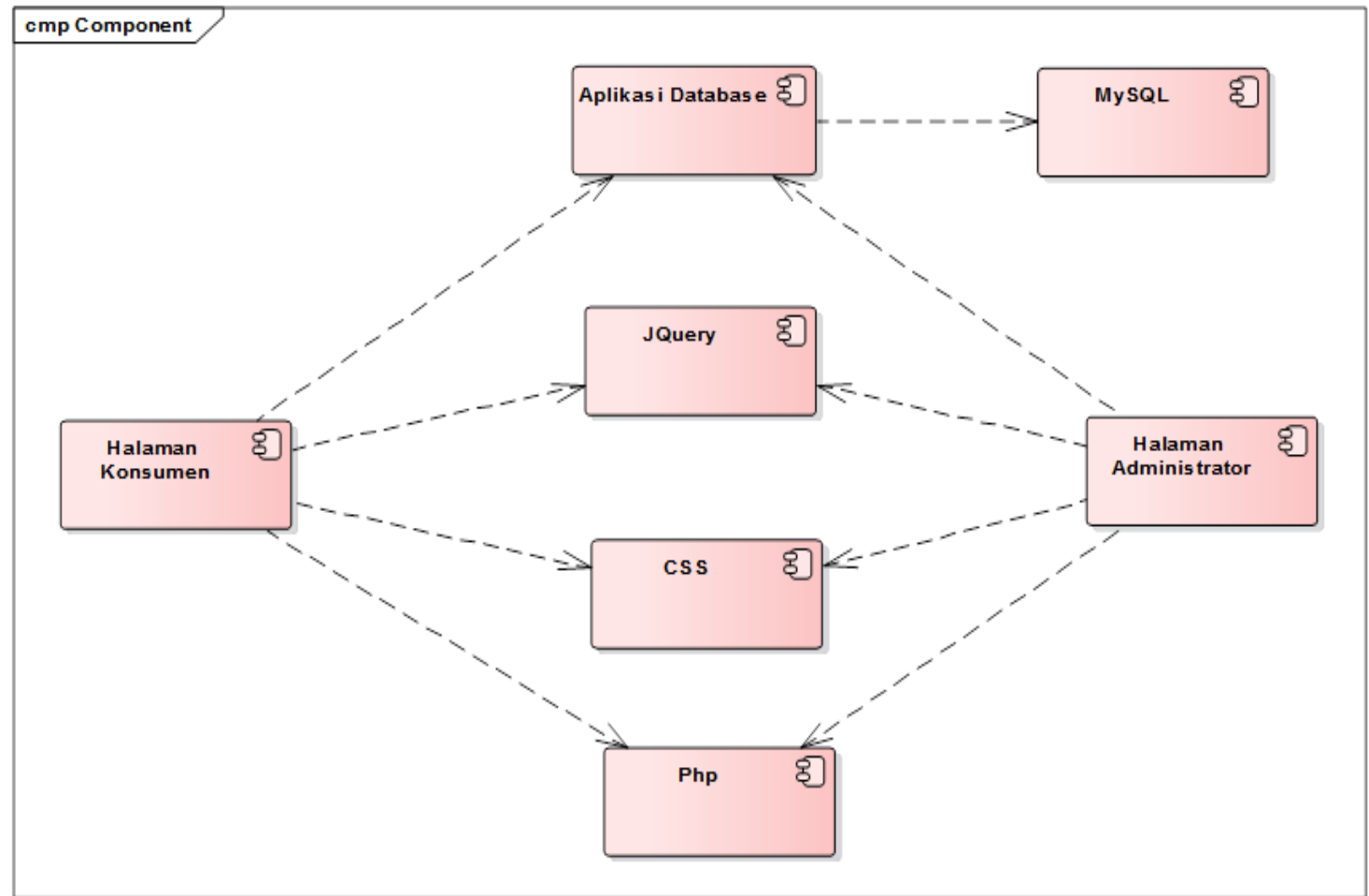

Gambar 4. Component Diagram 
Berikut merupakan Deployment Diagram:

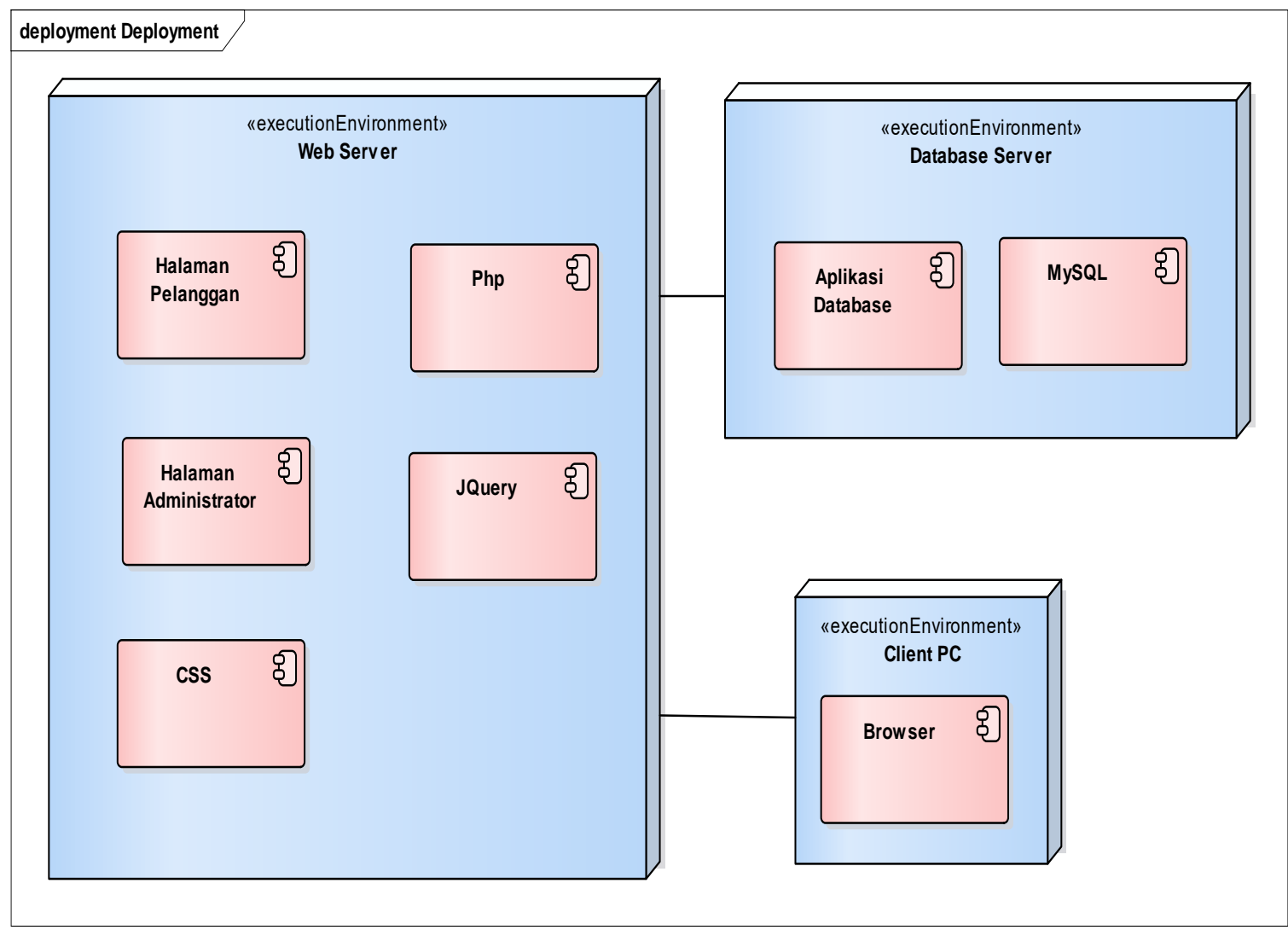

Gambar 5. Deployment Diagram

Berikut merupakan tampilan Home:

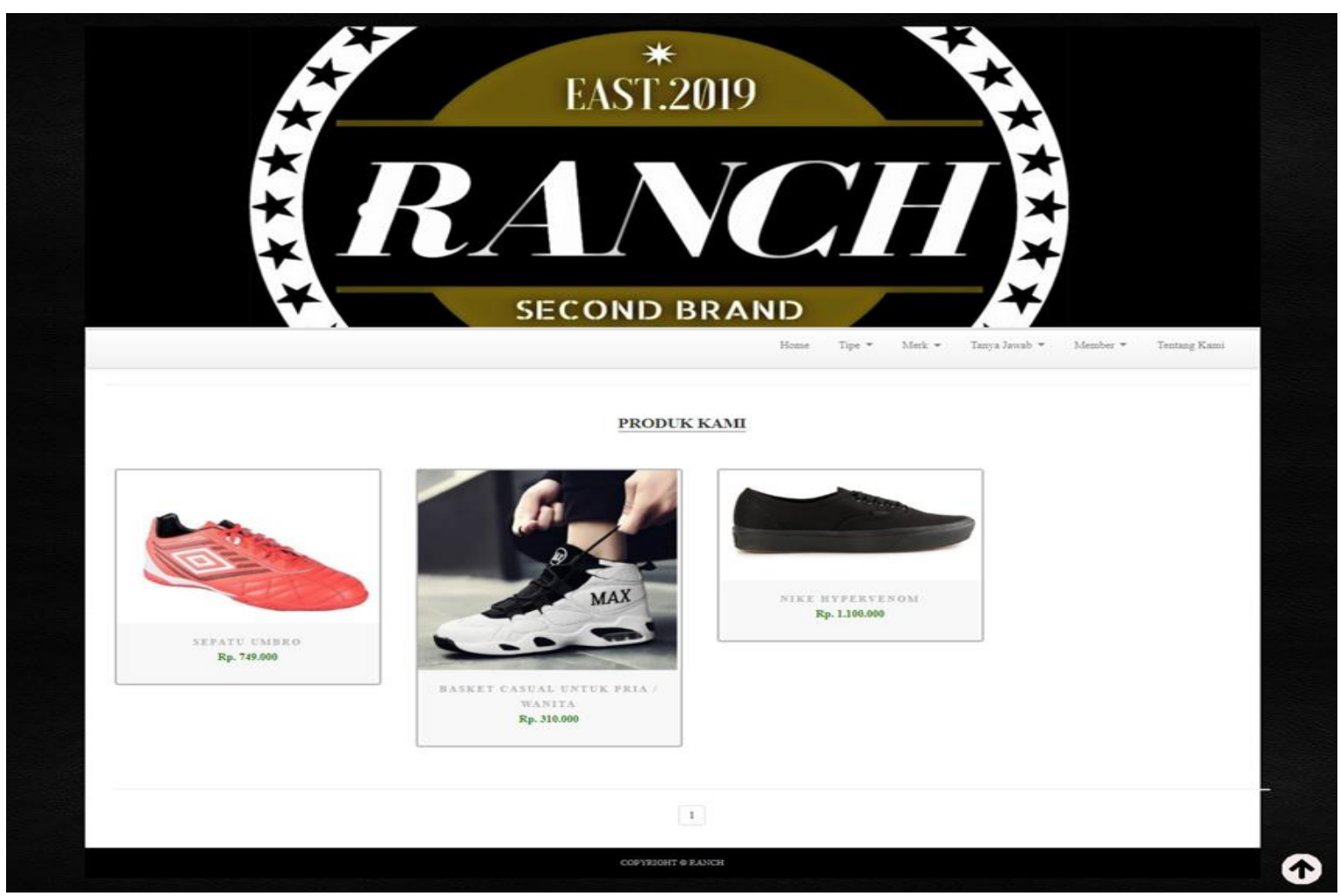

Gambar 6. Tampilan Halaman Home 
Tampilan yang ada ketika pelanggan akan melakukan komfirmasi pembayaran, yaitu ketika pelanggan sudah melakukan pembelian dan pembayaran adalah:

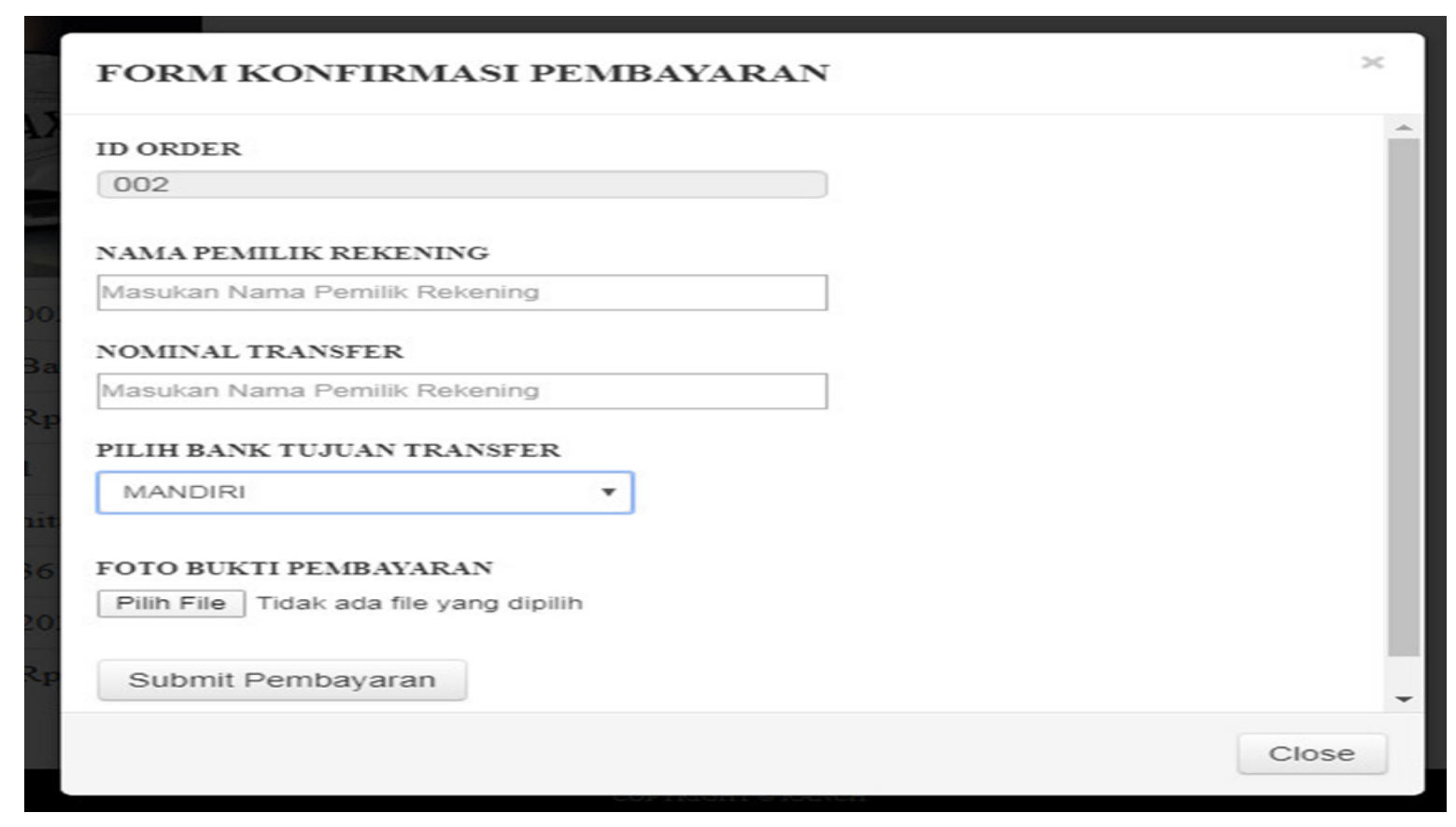

Gambar 7. Tampilan Halaman Konfirmasi Pembayaran

Dalam penelitian ini dilakukan pengujian untuk mengetahui kesalahan yang ada dalam pembuatan aplikasi. Pengujian yang dilakukan dengan menggunakan Black Box seperti dibawah ini: 


\section{Tabel 3.}

Hasil Pengujian Black Box Testing Halaman Form Login Admin

\begin{tabular}{|c|c|c|c|c|c|}
\hline No. & Skenario Pengujian & Test Case & $\begin{array}{ll}\text { Hasil yang } \\
\text { diharapkan }\end{array}$ & $\begin{array}{l}\text { Hasil } \\
\text { Pengujian }\end{array}$ & Kesimpulan \\
\hline 1. & $\begin{array}{l}\text { User Name dan } \\
\text { password tidak diisi } \\
\text { kemudian klik } \\
\text { tombol login }\end{array}$ & $\begin{array}{l}\text { User Name: } \\
\text { (kosong) } \\
\text { Password: } \\
\text { (kosong) }\end{array}$ & $\begin{array}{l}\text { Sistem akan menolak } \\
\text { akses user dan kembali } \\
\text { ke menu login admin } \\
\text { dan akan muncul pesan } \\
\text { "Isi bidang ini" }\end{array}$ & $\begin{array}{l}\text { Sesuai } \\
\text { Harapan }\end{array}$ & Valid \\
\hline 2. & $\begin{array}{l}\text { Mengetikkan user } \\
\text { name dan password } \\
\text { tidak diisi kemudian } \\
\text { klik tombol login }\end{array}$ & $\begin{array}{l}\text { User Name: } \\
\text { admin } \\
\text { Password : } \\
\text { (kosong) }\end{array}$ & $\begin{array}{l}\text { Sistem akan menolak } \\
\text { akses user dan kembali } \\
\text { ke menu login admin } \\
\text { dan akan muncul pesan } \\
\text { "Isi bidang ini" }\end{array}$ & $\begin{array}{l}\text { Sesuai } \\
\text { Harapan }\end{array}$ & Valid \\
\hline 3. & $\begin{array}{l}\text { User Name tidak diisi } \\
\text { dan password diisi } \\
\text { kemudian klik } \\
\text { tombol login }\end{array}$ & $\begin{array}{l}\text { User Name: } \\
\text { (kosong) } \\
\text { Password: } \\
\text { admin }\end{array}$ & $\begin{array}{l}\text { Sistem akan menolak } \\
\text { akses user dan kembali } \\
\text { ke menu login admin } \\
\text { dan akan muncul pesan } \\
\text { "Isi bidang ini" }\end{array}$ & $\begin{array}{l}\text { Sesuai } \\
\text { harapan }\end{array}$ & Valid \\
\hline 4. & $\begin{array}{l}\text { Mengetik User Name } \\
\text { dengan benar dan } \\
\text { Mengetikkan salah } \\
\text { pada Password dan } \\
\text { kemudian klik tombol } \\
\text { login }\end{array}$ & $\begin{array}{l}\text { User Name: } \\
\text { admin } \\
\text { (benar) } \\
\text { Password: } \\
\text { admi } \\
\text { (salah) }\end{array}$ & $\begin{array}{l}\text { Sistem akan menolak } \\
\text { akses user dan kembali } \\
\text { ke menu login admin. }\end{array}$ & $\begin{array}{l}\text { Sesuai } \\
\text { Harapan }\end{array}$ & Valid \\
\hline 5. & $\begin{array}{l}\text { Mengetikkan User } \\
\text { Name dan password } \\
\text { dengan data yang } \\
\text { benar kemudian } \\
\text { klik tombol login }\end{array}$ & $\begin{array}{l}\text { User Name: } \\
\text { admin } \\
\text { (benar) } \\
\text { Password: } \\
\text { admin } \\
\text { (benar) }\end{array}$ & $\begin{array}{l}\text { Sistem menerima akses } \\
\text { login dan kemudian } \\
\text { masuk ke halaman } \\
\text { administrator. }\end{array}$ & $\begin{array}{l}\text { Sesuai } \\
\text { Harapan }\end{array}$ & Valid \\
\hline
\end{tabular}




\section{KESIMPULAN DAN REKOMENDASI}

Berdasarkan hasil penelitian dan perancangan yang telah dilakukan dalam pembangunan aplikasi e-commerce pemasaran sepatu pada Toko Ranch_19, maka dapat disimpulkan bahwa dengan adanya website ini, penyebaran informasi produk pada Toko Sepatu Ranch_19 Jakarta lebih luas, sehingga pelanggan mengetahui keberadaan Toko Sepatu Ranch_19 Jakarta. Dengan komputerisasi pengolahan data penjualan pada Toko Sepatu Ranch_19 Jakarta lebih efektif dan efisien. Pelaporan penjualan dapat terkontrol dengan baik oleh pemilik Toko Sepatu Ranch_19 Jakarta.

Rekomendasi dari analisa aspek manajerial, harus adanya perencanaan, pelatihan dan pengawasan user yang akan menggunakan sistem informasi berbasis web ini, agar administrator mengetahui bagaimana cara menjalankan sistem informasi penjualan sepatu pada Toko Sepatu Ranch_19 Jakarta. Rekomendasi dari analisa aspek sistem atau program, diperlukan adanya pemeliharaan yang baik dan rutin terhadap perangkat keras dan perangkat lunak yang digunakan, untuk menghindari terjadinya kesalahan maupun kerusakan.Rekomendasi dari aspek penelitian selanjutnya, mengembangkan sistem lebih lanjut seperti menambahkan fitur chat sebagai layanan sistem informasi penjualan secara online.

\section{REFERENSI}

Dirgahinta, F., \& Anwar, S. N. (2018). Aplikasi E-Commerce Penjualan Sepatu Dengan Metode Cross Selling Pada Toko Pantes. Prosiding SINTAK 2018, 164-170.

Handayani, S. (2018). Perancangan Sistem Informasi Penjualan Berbasis E-Commerce Studi Kasus Toko Kun Jakarta. ILKOM Jurnal Ilmiah, I0(2), 182. https://doi.org/10.33096/ilkom.v10i2.310.182-189

Imaniawan, F. F. D., \& Elsa, U. M. (2017). Sistem Informasi Penjualan Sepatu Berbasis Web Pada Vegas Hyper Purwokerto. IJSE - Indonesian Journal on Software Engineering, 3(2), 82-91.

Lesmono, I. D. (2018). Rancang Bangun Sistem Informasi Penjualan Sepatu Berbasis Website Dengan Metode Waterfall. Jurnal Swabumi, 6(1), 55-62.

Lubis, B. O. (2016). Sistem Infromasi Penjualan Vouceher Belanja pada PT . Plaza Indonesia Reality Tbk. Jakarta. Informatika, 3(1), 51-62. 